obscure signs of fluctuation. Introducing the finest needle of the aspirator 1 obtained pus; I now withdrew this and introduced the second largest aspirating trocar and $d r \in W$ out nine ounces of thick yellow pus, odourless and without clots. The abscess cavity (a single large one) was then thoroughly xoshed out with ten ounces of a solution of chloride of zinc (half a grain to the ounce), an injection made of successive portions of two ounces at a time, and finally two ounces of the solution left in. An antiseptic pad was placed over the puncture, and a flannel bandage put firmly on around the abdomen and thorax. Complete anæsthesia was maintained througbout the operation. The patient was put on beef-tea diet and milk $a \bar{d} l i b$., with five-grain doses of chloride of ammonium three times a day. At my evening visit I found the patient up in bed and evidently quite contented. She had complained of no pains. The temperature from $97^{\circ}$ before the operation had risen to $99^{\circ}$ in the afternoon, but there was no teverish feel about her.

Jan. 21st.-8 P.M.: Passed a good night; slept well; one stool this morning. Temperature $98^{\circ} .-5$ P.M.: Temperature $101^{\circ}$. Feverish and restless; no stool since last note; skin dry. Ordered : mist. alb. (hosp.), six drachms; syr. simpl, six drachms; ft. hst. statim. Tepid spongings later on if necessary.

22nd.-The temperature continued to rise last night till midnight, when it reached $103^{\circ}$. As the skin was acting fairly well, the tepid spongings were omitted; no rigors. After midnight the bowels began to act, and with their action the temperature began to fall, till at 6 P.M. it was $98^{\circ}$. During the day the bowels acted four times. Quinine in doses of one grain and a half, with three minims of dilute hydrochloric acid, were now added to each dose of the ammonium chloride mixture. Evening temperature $99^{\circ}$.

23rd.-Morning temperature $97^{\circ}$; evening temperature 99. Three stools during the day.

24th.-Morning temperature $97^{\circ}$; evening temperature $100^{\circ}$. Three stools during the day. The tumour is slightly increased in size.

25th.-10 A.M.: Temperature $99^{\circ}$. The patient was feverish and restless during the night; no distinct rigors, liowever. Has had two stools during the morning. Under chloroform the abscess was aspirated, and five ounces of creamy yellow pus, without any perceptible smell, evacuated. The cavity was thoroughly washed out with a solution of chloride of zinc of the same strength as before, and an ounce of the solution finally left in.-5 P.M.: Temperature fell to $38^{\circ}$ after the operation, but rose again to $99^{\circ}$ during the afternoon. The patient has had three stools since 10 A.M. Seems cheerful.

26th to 29th-With an average number of three stools each day, the temperature varied between $97^{\circ}$ and $99^{\circ}$ on the 26th, $98^{\circ}$ and $100^{\circ}$ on the 27 th, and $98^{\circ}$ and $103^{\circ}$ on the $29 \mathrm{ch}$. The general condition up to the evening of the $29 \mathrm{th}$ seemed satisfactory; the patient cheerful, and taking her food well.

30th.-10 A.M.: The patient was feverish and restless all right; no rigors, however, or profuse perspiration. The skin at present is hot and dry, the temperature being $100^{\circ}$ and the little patient looks altogether ill. She was put ander chloroform and the abscess again aspirated; six ounces of thick, brownish-yellow, fetid pus, with numerous fiakes of broken-down liver tissue and clots, were with some diffleulty evacuated through the largest size aspirating trocar. The cavity was then thoroughly washed out with (first) twelve ounces of a solution of chloride of zinc, one grain to the ounce, and finally with about ten ounces of a solution of half the strength, two ounces of which were eventually left in. Slight hæmorrhage occurred in the abscess towards the end of the operation. And now the suestion of a free opening and insertion of a drainage tube again presented itself, but this time more forcibly. Taking into consideration the extreme restlessness of the little patient, the difficulty invariably experienced when she was being put under chloroform, the violent contractions of the abdominal muscles, which on the first occasion threatened rupture of the wall of the abscess, and as the cavity had been thoroughly washed out, I decided not to make a free incision. An antiseptic pad of flannel bandages was accordingly applied as before.-5 P.M.: Temperature $101^{\circ}$. Three stools sinee last note. The child was up playing with her mother, and apparently quite happy.

On the next and the following days the temperature oscil-

iated between $98^{\circ}$ and $101^{\circ}$, the bowels acting regularly. On

Feb. 2nd the dose of quinine was increased to three grains three times a day. On the evening of this day the temperature rose to $103^{\circ}$, but after this it gradually fell, with slight oscillations, till Feb. 8th, when it was $98^{\circ}$; and from this date it remained normal till the patient left the hospital. She rapidly gained flesh, and all signs of further liver truable disappeared.

On Feb. 7th, and also on the 20th, before discharging her from the hospital, I made a careful examination of the liver, but all signs of recent mischief had disappeared. Seen five weeks after her discharge from hospital, she had gained flesh and was looking quite well.

Remarks. - Besides being interesting as a sequel of malarial fever-an uncommon result on the Gold Coast, so far as my experience extends,-this case is noteworthy on account of (1) the age of the patient, (2) her sex, and (3) the successful result of the treatment. For these reasons $I$ desire to place it on record.

Accra, Gold Coast, West Africa.

\section{A đHirror}

\section{HOSPITAL PRACTICE, BRITISH AND FOREIGN.}

Nulla autem est alia pro certo noscendi via, nisi quamplurimas et morborum et dissectionum historias, tum aliorum tum proprias collectas habere, et inter se comparare.-MonGAGNI De Sed. et Caus. Morb., lib. iv. Proœmium.

\section{ST. THOMAS'S HOSPITAL.}

A CASE OF MYDROPHOBIA; DEATH; NECROPSY.

(Under the care of Dr. ORD.)

THIs case is chiefly remarkable for the long period of time which elapsed between the inoculation and the development of the disease, which ran an acute course. It would appear that in the majority of instances hydrophobia develops during the four months which immediately follow the infliction of the bite; in this case it was apparently two years. Much temporary relief was obtained by the use of the ether spray applied to the back of the neck. For the following account we are indebted to Mr. S. W. Wheaton, house-physician.

The patient, aged six years and a half, a well-nourished boy, was admitted on May 16th. He was bitten over the left eye two years previously by a dog eupposed by the bystanders to be mad. The wound was rery slight, and was not treated in any way. After complaining of tenderness over the left eye for some days, he was observed on the evening of the 15 th to be rolling on the floor and complaining of headache; he also complained of a pain in the abdomen and toothache on the left side. On being put to bed he refused food, and when anything to drink was brought near him he struggled and tried to knock it over. On the 16th he began to make a peculiar cry, and had "catching of his breath"; he became very excited when touched or when offered anything to drink. He was therefore brought to the hospital.

When admitted the boy was in a condition of great excitement and extreme terror; the pupils were widely dilated; he was constantly looking about wildly, and was very excited when anyone approached him, but after a time quieted down. The respirations were very irregular, and occasionally there were spasmodic contractions of the diaphragm, producing a peculiar noise, like a long-drawn hiccough, ending in a shrill scream. He lay upon his back, with legs drawn up and head retracted; there wes active rigidity of both arms and legs. When anything was offered him to drink he jerked about in the bed violently, and tried to knock it over with his hands; directly fluid entered the mouth it was ejected violently, his face became livid, the pupils dilated, respiration interrupted, extremities rigid, and back arched. There was a small superficial scar over the left eyebrow, but no redness over it; also bright injection of the fauces, but no swelling; the submaxillary glands were a little enlarged, but not tender; but pressure over the larynx was especially painful. When micturating he had an attack of general convulsions; the urine contained a large amount of albumen, but no sugar, and a deposit of 
ammonium urate was present. Bowels confined. He was fed by the nasal tube, and bromide of potassium was given. On the 17th the patient continued still in a ccndition of wild excitement, and the sight of a cup of milk produced general convulsive movements, which began to recur every ten minutes; in the intervals he was quiet, would talk to the nurse, and complained still of toothache. At 11 A.M. the convulsions became more frequent, and he was constantly ejecting frothy fluid from the mouth. The ether spray was applied to the back of the neck, after which the convulsions ceased, and he drank for the first time by the mouth. He remained quiet until 12.30, when the paroxysms returned, and ether spray was again used; after this he was quiet until 4 P.M., when he had a severe convulsive attack, with great rigidity of arms and legs, retraction of the head, and arching of the back, and was ejecting frothy mucus from the mouth mixed with grumous fluid. The ether spray was applied again, but this time, on feeding, some of the fluid was ejected from the mouth. After this he spoke sensibly, was much amused with a watch and a penny, but said that the bed was full of spiders. At 6 P.M. he was again seized with general convulsive movements, and vomited a large amount of grumous fluid; the pupils became greatly dilated; he appeared to have hallucinations, laughing and looking about wildly. Respiration gradually ceased, the heart continuing to beat for nearly one minute after the last expiration.

At the post-mortem examination nothing abnormal was found except great congestion of the organs, especially the lungs.

\section{HALIFAX INFIRMARY.}

PURULENT DISCHARGE FROM THE FAR, FOLLOWED BY DIFEUSE SUPPURATIVE MENINGITIS; DEATH; NECROPSY. (Under the care of Dr. S. C. Smrth.)

$\mathrm{WF}$ are indebted for the notes of this case to $\mathrm{Mr}$. J. P. Gray, house surgeon.

Thomas $\mathrm{M}-$, aged twenty-six, admitted April 22nd, 1887. Has had purulent dissharge from the ear for ten years. A week before admission he began to have severe pain just behind the right ear, and on the night before admission he first noticed that he could not shut his right eye.

On admission the man was pale but well nourished, with a rather anxious expression. There was a profuse offensive discharge from the ear. At the bottom of the meatus was a prominent red granulation. He was quite deaf in this ear, and had been so for several years. A watch, however, placed on the head could be heard distinctly. He had total right facial paralysis. He answered questions readily, and had no hemiplegia. Urine: sp. gr. 1024; acid; no albumen or sugar. Temperature $101 \cdot 2^{\circ}$

He continued in this condition for three days, his ear being syringed out frequently. The discharge was still very profuse.

April 26th. - The temperature had suddenly risen to $104.2^{\circ}$ this morning. Is dull and apathetic, and becomes confused when asked questions. Pupils equal and act to light.

27th.-Patient has become semi-comatose. Plantar reffex lost on left side, and partial loss of sensibility in left leg, but no loss of power; no loss of power or sensation in lett arm. Delirious at intervals. The same evening the left leg had become paralysed and completely anæsthetic. Left arm had lost power, but did not seem to be anæsthetic at all. Accordingly, Dr. Smith trephined, at 7 P.M., over the mastoid cells with a one-third of an inch trephine. Nopus was, however, reached. The head was shaved and the ear syringd out with a 1 in 20 carbolic lotion and stuffed with iodoform, in order to make it as aseptic as possible, with a view to possible trephining higher up on the following day. Temperature $103.8^{\circ}$

28th.-Patient completely comatose. Total left hemiplegia and hemi-anæsthesia. Cheyne-Stokes' respiration. No pus from trephine wound. Left cornea quite insensitive, but pupil acts very sluggishly to light. Temperature $101^{\circ}$. Right pupil also acts to light.

29th.--Right pupil dilated, and does not act to light. Right external strabismus. Right cornea anæsthetic.11 P.M. Spasmodic twitchings in left hand and arm, lasting about two minutes at a time. The head also turns to the left. Stertorous breathing. Pulse 170; temperature $1026^{\circ}$.

30th.--Died at 8 A.M. Temperature just before death $106^{\circ}$.

Necropsy, four hours after death.-Right hemisphere bathed in thick fetid pus, flattened, and very hyperæmic.
About eight ounces of pus were collected. The base of the brain was also bathed in it. On the posterior surface of the right petrous bone was a small hole in the dura mater, admitting a fine probe. On stripping off the dura mater, a hole was found in the roof of the tympanum, through which a probe could be passed into the tympanum and out at the external meatus. For about half an inch all round the upper end of this unnatural foramen, the dura mater had been separated from the bone, so as to form a small abscess cavity (of old standing probably), which had apparently burst through the dura mater about the time of admission, and caused the cerebral symptoms. The brain on section. was found quite healthy.

\section{CROMER COTTAGE HOSPITAL.}

A CASF OF CHRONIC EMPYEMA TREATED BY ESTLANDER'S METHOD；CURE； REMARKS.

(Under the care of Dr. H. McCluRE.)

R. W-, aged twenty-one, was admitted on Nov. 29th, 1886. Family history fairly good. His presentillness dates from a pleurisy six years ago. In November, 1883, he was in Cromer Cottage Hospital with an empyema of the left side, and under free drainage the discharge ceased. In April, 1885, pus was again issuing from the side; the point of exit was enlarged, free drainage secured, and the discharge again ceased. From this time he continued in indifferent health till May, 1886, when he was admitted to the Norwich Hospital with an open empyema. He left the hospital after a residence of two months, the discharge still continuing, and in September the side burst at another point higher up, so that now there were two openings, both giving exit to fetid pus. This state of matters continued up to the time of his admission in November.

On admission the patient was found to be fairly well nourished, but anæmic, with rather livid features and with most marked clubbing of the fingers, cough, and expectoration. The heart's impulse was half an inch below the nipple. and an inch and a half to the right of the nipple line. The respiratory sounds over the right lung were normal; on the left side no true vesicular murmur was heard, except in a small space under the clavicle; dulness not absolute behind from half-way down the scapula. There were two openings in the chest wall, one below the eighth rib in the axillary line, the other in the sixth interspace, both discharging fetic pus freely. Both openings were enlarged, and a metal sound passed into the upper gave vent to a gush of very fetid pus, a loculated collection evidently having been tapped, $T$ wo large drainage tubes were then inserted.

The patient seemed to improve at first, the general health was better, and the discharge less, and, further, the upper opening closed; but at the end of three months there had been no material progress made. The discharge from the lower opening was still free; iodoform insufflations were used, keeping the discharge aseptic. There were also cough lividity, and most marked clubbing of the fingers. As the side had been discharging pus for nearly a year, with a history of bad health for eighteen months, and there being not the slightest prospect of the empyema healing, resection of the ribs was determined on, and this was carried out on March 4th, 1887. Mr. Fenner kindly consented to help, and Mr. Mackintosh gave the A. C. E. mixture. An incision was made along the sixth rib, beginning about two inches outside the nipple line and reaching about four inches outwards. The periosteum was bared, and an incision made through it along the rib. About an inch of the rib in the middle of the incision was removed, being raised by a periosteum elevator and cut through with ordinary bone forceps. A further incision was then made from the inner point of the first for three inches downwards, the skin reflected, and the seventh rib bared, and a piece of about two inches and $a$ quarter in length removed in the same way; the corresponding pieces of periosteum were also excised. The pleura was then snipped through with scissors, and was found to bo almost an inch thick. There was now a large gaping hole in the chest wall of over an inch in diameter. The finger was introduced and the cavity thoroughly explored; it was found to reach backwards for three or four inches from the opening upwarc, where it was roofed by the lung for about two inches, and downwards about three inches. It was bounded in front by the pericardium, through which the heart's pulsations were distinctly felt by the finger. The cavity throughout 